\title{
СОСТОЯНИЕ ВНЕШНЕЭКОНОМИЧЕСКИХ СВЯЗЕЙ ПРОМЫШЛЕННЫХ ПРЕДПРИЯТИЙ СТРАНЫ И ПУТИ ПОВЫШЕНИЯ ИХ ЭКСПОРТНОГО ПОТЕНЦИАЛА (НА ПРИМЕРЕ ОOО «LOS GIGANTES TEXTILES»)
}

\author{
Олимова Нодира Хамракуловна \\ кандидат экономических наук, доцент \\ Ферганский государственный университет, \\ 2. Фергана, Узбекистан
}

\begin{abstract}
Аннотация. В работе рассматриваются вопросы внешнеэкономической деятельности национальной экономики, которая стремительно развивается и становится все более конкурентоспособной. Анализируется состояние экспорта, который стал важнейшим направлением деятельности промышленных предприятий, являющимся критерием оценки развития экономики страны в целом.

Annotation. The paper deals with the issues of foreign economic activity of the national economy, which is rapidly developing and becoming more competitive. The state of export is analyzed, which has become the most important area of activity of industrial enterprises, which is a criterion for assessing the development of the country's economy as a whole.

Ключевые слова: предприятия, внешнеэкономические связи, экспорт, оборудование, импорт

Key words: enterprises, foreign economic relations, export, equipment, import
\end{abstract}

Приоритетной задачей развития цифровой экономики в нашей стране является обеспечение стремительного роста экономики Узбекистана, ускорение ее интеграции на международную арену и, как следствие, включение Узбекистана в список демократических, экономически развитых стран.

Основной функцией Стратегии действий по пяти приоритетным направлениям развития Республики Узбекистан на 2017-2021 годы является либерализация и упрощение экспортной деятельности, диверсификация экспортной структуры и географии, расширение экспортных возможностей секторов экономики и экономики регионов. Это факт, что развитие внешнеэкономической деятельности является одним из факторов, ускоряющих развитие экономики в решении этой задачи, которая включена в План действий.

Внешнеэкономическая деятельность нашей национальной экономики стремительно развивается и становится все более конкурентоспособной. Экспорт стал важнейшим направлением деятельности предприятий, критерием оценки развития экономики в целом. Сегодня практически все наши отрасли и предприятия полностью вовлечены во внешнеэкономическую деятельность и активно осваивают зарубежные рынки.

На заседании Кабинета Министров Республики Узбекистан об итогах социально-экономического развития страны в 2019 году и важнейших приоритетах углубления экономических реформ в 2020 году в общей сложности в 2019 году на международных финансовых рынках было потрачено 7,7 млрд. сумов. на проведение промышленных ярмарок в Ташкенте и за рубежом. Реализованы соглашения об экспорте предприятий в регионы страны. В России, Казахстане, Туркменистане, Украине и Республике Беларусь, а также в других странах активизировался поиск новых рынков сбыта. Такое увеличение экспорта, составляющего основу внешнеэкономической деятельности Республики Узбекистан, связано не с поставкой нам традиционных ресурсов - хлопкового волокна, драгоценных металлов и различного сырья, а в основном автомобилей, нефтехимии и металлопродукции, минеральных удобрений, пряжи и текстиля, трикотажных изделий, кабельно-проводниковой продукции, строительных материалов и многих других аналогичных экспортных товаров, предоставляющихся в обмен на увеличение объемов и разнообразия. Это подтверждается увеличением доли готовой продукции и услуг в экспорте, при этом доля хлопкового волокна значительно снизилась.

Говоря об элементах экспортного потенциала, необходимо, прежде всего, обратить внимание на его классификацию по определяющим признакам. На наш взгляд, одним из основных критериев классификации экспортного потенциала является его ресурсный источник.

Основные источники сырья для «Los Gigantes Textiles» закупаются на договорной основе у «Узпахтасаноат» с момента его основания, а с 2018 года кластеры закупаются у кластеров в Андижанской, Наманганской и Ферганской областях. Предприятие оснащено прядильными машинами швейцарской компании «RIETER». B настоящее время по проекту Президента Республики Узбекистан от 21.12.2016 №ПК-2687 на предприятии устанавливаются машины немецкой компании «SCHLAFHORST».

Проект запущен в третьем квартале 2018 года (таблица 1) [5]. 
Таблица 1

Данные по импорту ООО «Los Gigantes Textiles» в 2017-2019 гг.

\begin{tabular}{|c|c|c|c|c|c|c|}
\hline \multirow[b]{2}{*}{ Корхона номи } & \multicolumn{2}{|r|}{2017 г. } & \multicolumn{2}{|r|}{2018 г. } & \multicolumn{2}{|c|}{2019 г. } \\
\hline & $\begin{array}{l}\text { Импорт } \\
\text { (долЛ. } \\
\text { США) }\end{array}$ & $\begin{array}{c}\text { Импор-тируемая } \\
\text { продукция }\end{array}$ & $\begin{array}{l}\text { Импорт } \\
\text { (долл. } \\
\text { США) }\end{array}$ & $\begin{array}{c}\text { Импор-тируемая } \\
\text { продукция }\end{array}$ & $\begin{array}{l}\text { Импорт } \\
\text { (долл. } \\
\text { США) }\end{array}$ & $\begin{array}{c}\text { Импор-тируемая } \\
\text { продукция }\end{array}$ \\
\hline $\begin{array}{l}\text { OOO «Los } \\
\text { Gigantes } \\
\text { Textiles» }\end{array}$ & 578626 & $\begin{array}{c}\text { Производственное } \\
\text { оборудова-ние и } \\
\text { запасные части }\end{array}$ & 5242 & $\begin{array}{c}\text { Производственное } \\
\text { оборудова-ние и } \\
\text { запасные части }\end{array}$ & 7554 & $\begin{array}{c}\text { Производст } \\
\text { венное } \\
\text { оборудова-ние и } \\
\text { запасные части }\end{array}$ \\
\hline
\end{tabular}

Как видно из таблицы 1, компания импортировала производственное оборудование и запасные части на общую сумму 578626 долларов США в 2017 году, станки и запасные части на сумму 5242 доллара США в 2018 году и станки и запасные части на сумму 7554 долл. США запчасти в 2019 году. Это означает, что у компании есть спрос на данную продукцию, поэтому эффективная реализация программы локализации в Узбекистане будет способствовать производству экспортно-ориентированной продукции, занятости, улучшению региональной инфраструктуры, дальнейшему ускорению промышленного развития, снижению цен.

Увеличение количества предприятий, производящих импортозамещающую продукцию в нашей стране, напрямую связано с созданной в нашей стране благоприятной деловой средой.

В результате ассортимент продукции под маркой «Сделано в Узбекистане» расширяется на рынках нашей страны.

Экспортный потенциал: делится на внутренний и внешний экспортный потенциал. Внутренний экспортный потенциал включает совокупность природных, трудовых, финансовых, материальных и информационных ресурсов, необходимых для производства продукции на экспорт. Решающим фактором здесь является не только наличие этих ресурсов, но и эффективность их использования. Потенциал зарубежного экспорта включает продажу продукции, конкурирующей на внешних рынках, сбытовую, логистическую и сервисную деятельность предприятия. В экономической литературе также проводится классификация экспортного потенциала применительно к рынкам сбыта продукции. По ее словам, экспортный потенциал:

1. Экспортный потенциал существующего продукта на занятом рынке.

2. Экспортный потенциал существующего продукта на рынке будущего.

3. Экспортный потенциал нового продукта на занятом рынке.

4. Экспортный потенциал новых продуктов на рынке будущего.

Продукция OOO «Los Gigantes Textiles», которую мы анализируем, экспортируется на зарубежные рынки в Китай и Турцию [6]. На внутреннем рынке он в основном продается на договорной основе в Наманган, Андижан, Маргилан и Коканд. Система показателей используется для помощи в оценке экспортного потенциала предприятия и уровня его использования. Показатель объема используется для определения производственной мощности промышленного предприятия.

Используя этот метод определения индекса экспортного потенциала промышленного предприятия, можно выявить конкурентоспособность, сильные и слабые стороны предприятия, найти пути повышения его эффективности, проанализировать производственные мощности предприятия и одновременно сравнить соответствующие показатели предприятий-конкурентов (таблица 2) [5].

Данные по экспорту OOO «Los Gigantes Textiles» в 2017-2019 гг.

\begin{tabular}{|c|c|c|c|c|c|c|}
\hline \multirow{2}{*}{ Название OOO } & \multicolumn{2}{|c|}{2017 г. } & \multicolumn{2}{|c|}{2018 г. } & \multicolumn{2}{c|}{2019 г. } \\
\cline { 2 - 7 } & $\begin{array}{c}\text { Экспорт } \\
\text { (долл. }\end{array}$ & $\begin{array}{c}\text { Экспор- } \\
\text { тируемая } \\
\text { продукция }\end{array}$ & $\begin{array}{c}\text { Экспорт } \\
\text { (долл. } \\
\text { США) }\end{array}$ & $\begin{array}{c}\text { Экспор- } \\
\text { тируемая } \\
\text { продукция }\end{array}$ & $\begin{array}{c}\text { Экспорт } \\
\text { (долл. }\end{array}$ & $\begin{array}{c}\text { Экспор- } \\
\text { тируемая } \\
\text { продукция }\end{array}$ \\
\hline $\begin{array}{c}\text { OOO «Los } \\
\begin{array}{c}\text { Gigantes } \\
\text { Textiles» }\end{array}\end{array}$ & 308999 & Пряжа & 555000 & Пряжа & 245000 & Пряжа \\
\hline
\end{tabular}

Как видно из таблицы 2, основной экспортной продукцией предприятия является производство пряжи. В 2017 году компания экспортировала пряжи на сумму 308999 долларов США, в 2018 году этот показатель составил 555000 долларов США, а в 2019 году этот показатель составил 245000 долларов США. В 2019 году стало понятно, что причина снижения зависит от уровня спроса со стороны международных партнеров.

Одним из основных направлений экономических реформ в Узбекистане является развитие существующих производств и секторов услуг и создание новых производств. Цель этих задач - наполнить внутренний рынок 
качественными потребительскими товарами и создать возможности для экспорта на мировые рынки конкурентоспособных товаров, соответствующих международным стандартам, и производимой продукции.

Внешнеэкономическая деятельность экспортно-ориентированных предприятий регулируется двумя способами: первый - через рыночные механизмы внешнеэкономической деятельности; второй - государственное регулирование внешнеэкономической деятельности.

Основными рыночными механизмами регулирования внешнеэкономической деятельности являются цена, конкуренция, спрос, предложение и др. Изменения спроса и предложения на определенные товары, услуги и другие формы сотрудничества на мировом рынке оказывают прямое влияние на внешнеэкономический сектор страны. Приоритет отдается проведению активной инвестиционной политики, направленной на обеспечение быстрой модернизации и технического перевооружения предприятий, работающих в нашей стране.

Международная миграция капитала важна для развития мировой экономики, поскольку она укрепляет внешнеэкономические и политические связи страны, увеличивает внешнеторговый оборот экспортноориентированных предприятий, увеличивает производство, ускоряет экономическое развитие, повышает конкурентоспособность промышленных товаров в мировой рынок. и увеличивает занятость в стране [2].

В целом целесообразно реализовать следующие предложения по либерализации внешнеэкономических связей республики и дальнейшему совершенствованию комплекса внешнеэкономических связей:

- защита интересов участников внешнеэкономической деятельности Республики Узбекистан, как на внутреннем, так и на внешнем рынках;

- создание необходимых условий, направленных на стимулирование развития национальной экономики и ее интеграции в мировую экономику;

- дальнейшее совершенствование государственного регулирования внешнеэкономической деятельности;

- до последних лет внешнеторговый оборот с соседними странами не в полной мере отражал экономический потенциал страны. Мы можем и дальше увеличивать наш экспортный потенциал и укреплять наши позиции в международной торговле, в полной мере используя наши существующие возможности, используя практический опыт, накопленный развитыми странами, и своевременную реализацию предложений;

- разработка и реализация государственных программ, направленных на развитие экспортного потенциала;

- создание агентств по развитию экспорта (Государственное агентство по управлению малым бизнесом);

- развитие системы экспортного страхования и экспортных кредитных агентств;

- желательно укреплять экономические связи со странами, которые продолжают позитивные торговоэкономические отношения с США. Например, Индия. Индия - вторая по численности населения страна на рынке;

- следующие цели - Япония и Южная Корея. Хотя Южная Корея является для нас стратегическим торговым партнером, у нас остается отрицательный баланс. Япония - это гигантский рынок, который импортирует продукции на сумму почти 600 миллиардов долларов в год, и нам необходимо овладеть правилами японского рынка;

- для новых рынков важно будет заключать торговые соглашения в новом духе и вступать во Всемирную торговую организацию;

- дальнейшее совершенствование систем, полностью поддерживающих деятельность производителей и экспортеров;

- дальнейшее расширение сотрудничества с зарубежными странами в области стандартизации современных технологий, метрологии и сертификации качества;

- расширение создания совместных предприятий в различных регионах страны с целью привлечения прямых иностранных инвестиций и производства продукции, соответствующей международным стандартам и конкурентоспособной на мировом рынке;

- дальнейшее расширение торгово-экономического и финансового сотрудничества Республики Узбекистан с зарубежными странами и другими субъектами международного права;

- улучшение снижения транспортных расходов на экспортные товары за счет развития международных транспортных коммуникаций.

Для эффективной организации внешнеэкономических связей и дальнейшего развития экспортного потенциала нашей страны рекомендуется [3]:

- прежде всего, чтобы создать стабильные и предсказуемые макроэкономические условия для стимулирования экспорта, обменный курс должен быть прежним;

- означает необходимость постоянного мониторинга человеческого фактора, подготовки и переподготовки специалистов;

- краткосрочные субсидии для стимулирования экспортного потенциала, наиболее удобная форма экспортного стимулирования - свободные экономические зоны;

- благоприятные климатические условия и традиционные навыки населения должны широко использоваться в развитии экспортного потенциала страны.

- необходимо глубокое исследование механизма повышения привлекательности иностранных инвестиций в экспортно-ориентированные предприятия. 
В связи с этим необходимо проанализировать возможность применения следующих стратегий увеличения экспортного потенциала [4]:

- достижение набора продуктов, поставляемых в определенный сегмент рынка, путем выявления, создания и применения растущих сегментов в рамках существующего внешнего рынка;

- стремление к инновациям, создающим бесценные конкурентные возможности;

- увеличить объемы экспорта и доходов за счет снижения стоимости продукции и ее доставки.

Таким образом, вышеуказанные взгляды позволят Узбекистану эффективно участвовать в мировом экономическом сообществе, своевременно устраняя проблемы, препятствующие совершенствованию и дальнейшему развитию географической структуры внешнеэкономических связей.

\section{Список литературы:}

1. Olimova, N.X., \& Axunova, O.E. (2020). Evaluation of the investment environment of fergana region and investment activity of real sector enterprises in it. // Новые информационные технологии, 102.

2. Олимова, Н.Х., \& Ахунова, О.Э. (2020). Способы эффективного развития инвестиционной деятельности предприятий реального сектора. // Архивариус, (7 (52)).

3. Akhunova O.E, Olimova N.Kh, Ergashev A.Kh. Role of innovative technologies in ensuring competitiveness of export products in Uzbekistan // Process management and scientific developments, 2019, 7-16p.

4. Олимова, Н. Х. (2019). Инновационные методы исчисления показателей эффективности и использование инновационных технологий в обеспечении конкурентоспособности продукции предприятия. // Тенденции развития мировой торговли в XXI веке (69-73c.).

5. Статистические данные Главного управления экономического развития и сокращения бедности Ферганской области.

6. Данные ОOО «Los Gigantes Textiles» по экономической деятельности в период 2017-2019гг. 